OPEN ACCESS

Edited by:

Fatima Ferreira,

University of Salzburg, Austria

Reviewed by:

Alain Jacquet,

Chulalongkorn University, Thailand

Enrique Fernandez-Caldas,

Inmunotek SL, Spain

Ronald van Ree,

Amsterdam University Medical

Center, Netherlands

*Correspondence:

Jeffrey M. Wilson

jmw2gc@virginia.edu

Specialty section:

This article was submitted to Allergens,

a section of the journal

Frontiers in Allergy

Received: 08 April 2021

Accepted: 03 June 2021

Published: 28 June 2021

Citation:

Keshavarz B, Erickson LD,

Platts-Mills TAE and Wilson JM (2021)

Lessons in Innate and Allergic

Immunity From Dust Mite Feces and

Tick Bites. Front. Allergy 2:692643.

doi: 10.3389/falgy.2021.692643

\section{Lessons in Innate and Allergic Immunity From Dust Mite Feces and Tick Bites}

\author{
Behnam Keshavarz ${ }^{1}$, Loren D. Erickson ${ }^{2}$, Thomas A. E. Platts-Mills ${ }^{1}$ and \\ Jeffrey M. Wilson ${ }^{1 *}$ \\ ${ }^{1}$ Division of Allergy and Immunology, Department of Medicine, University of Virginia, Charlottesville, VA, United States, \\ ${ }^{2}$ Beirne B. Carter Center for Immunology Research and the Department of Microbiology, Immunology and Cancer Biology, \\ University of Virginia School of Medicine, Charlottesville, VA, United States
}

Allergic diseases represent a major cause of morbidity in modern industrialized and developing countries. The origins and development of allergic immune responses have proven difficult to unravel and remain an important scientific objective. House dust mites (HDM) and ticks represent two important causes of allergic disease. Investigations into HDM fecal particles and tick bites have revealed insights which have and will continue to shape our understanding of allergic immunity. In the present review, focus is given to the role of innate immunity in shaping the respective responses to HDM and ticks. The HDM fecal particle represents a rich milieu of molecules that can be recognized by pathogen-recognition receptors of the innate immune system. Factors in tick saliva and/or tissue damage resultant from tick feeding are thought to activate innate immune signaling that promotes allergic pathways. Recent evidence indicates that innate sensing involves not only the direct recognition of allergenic agents/organisms, but also indirect sensing of epithelial barrier disruption. Although fecal particles from HDM and bites from ticks represent two distinct causes of sensitization, both involve a complex array of molecules that contribute to an innate response. Identification of specific molecules will inform our understanding of the mechanisms that contribute to allergic immunity, however the key may lie in the combination of molecules delivered to specific sites in the body.

\section{Keywords: allergens, allergic immunity, innate immunity, tick bite, IgE, lone star tick, $\alpha$-Gal, dust mite}

\section{INTRODUCTION}

Allergic immunity consists of a network of cells and mediators that are abundant in the skin and mucosal tissue. The system likely evolved as a rapid-defense mechanism to combat extracellular threats from helminths, ecto-parasites, and venomous animals $(1,2)$. However, in the industrial world this form of immunity is best known as the cause of allergic diseases, which generally occur as a result of aberrant immune activation to otherwise innocuous environmental antigens. Contemporary understanding of allergic immunity includes not only IgE but also a variety of other cells and mediators that include Th2 cells, ILC2 cells, mast cells, eosinophils, and basophils. Because Th2 cells play a critical role, allergic immunity is also often referred to as Th2-related, or type-2 (3). Despite the fact that it has been over 50 years since $\operatorname{IgE}$ was 
characterized, there remain many gaps in our understanding of the mechanisms and pathways that contribute to allergic immunity. Nonetheless, it is increasingly clear that the evolutionarily ancient innate immune system must play a critical role in shaping the development of allergic responses (4). There are two main ways that activation of the innate immune system could contribute to allergic disease. Firstly, agents which are recognized by the innate immune system could contribute to allergic symptoms via mechanisms that are independent of IgE antibodies. Secondly, innate immune pathways can provide inflammatory cues that promote IgE sensitization and/or maintenance of IgE. To frame this discussion about the role of innate immunity in allergic disease, here we focus on two taxonomically-related arthropods that have strong associations with allergic disease (5). Specifically, we discuss the relevance of house dust mite (HDM) feces and tick bites as discrete entities that are well established triggers of IgE responses. Our emphasis is on studies carried out in humans or with human samples, but we also touch on some animal studies that provide additional support.

\section{DUST MITES}

\section{Early Insights Into Dust Mite Allergy and the Relevance of Particles}

When house dust mites were first established as a major source of house dust allergens, which occurred around 1970 as children in the Western World were spending more and more time indoors, purification of the protein allergens from those acarids became an important objective. Many allergens were identified by cross radio immunoelectrophoresis. Those included "allergen 42," which Henig Lowenstein recognized as an important allergen (6). In 1978, Chapman purified Dermatophagoides pteronysinnus allergen 1 (Der p 1) and that rapidly led to the ability to measure the protein and to the recognition that the mite fecal particles were the major source of allergen that accumulated in cultures $(7,8)$. Work by Tovey (9) went on to establish that the fecal particle is the major form in which mite allergens become airborne in houses. Further, the size of those particles at 20-35 microns in diameter is such that they contain sufficient allergen for a single particle to induce a positive prick test in an allergic individual. Ultimately these particles turned out to be a treasure trove of different proteins and other molecules that could contribute to the immune response to an increasing list of fully defined protein allergens (see www.allergen.org). In many cases the allergens themselves had intrinsic capacity to activate innate immune pathways, though there were also many other biologically active molecules. These molecules included mite DNA, bacterial DNA, chitin, $\beta$-glucan and others (10, 11). Although important concepts and nomenclature in innate immunity had yet to be coined and described by the likes of Charles Janeway Jr., Ruslan Medzhitov, Bruce Beutler, and others, it is now clear that structurally diverse molecules present in HDM are recognized as "Pathogen-associated molecular patterns" (PAMPs) or "Danger-associated molecular patterns" (DAMPs) by the germline-encoded innate immune system $(4,12-14)$. This is facilitated by several families of pathogen-recognition receptors (PRRs) of which the Toll-like receptor (TLR) family is perhaps best known.

Considering the size and known contents of the mite fecal particles, it is interesting to think about the published evidence on delivery of innate receptor ligands and their efficacy as adjuvants. Medzhitov et al. (15) at Yale found clear evidence that the ligands need to be physically "close" to the relevant antigen. Thus, there is every reason to think that one or more PAMPs (or DAMPs) within the fecal particle are relevant to the immune response to the allergens (Figure 1). Taken together, mite allergens present an example where the activators of several innate pathways are inevitably physically close to the mite allergens. Equally, we would argue that the combination of the many different components in mite feces, in addition to the abundance of HDM allergen in dust, is what makes dust mite such a "good" allergen (17). In some countries the dominance of mite allergens in relation to asthma has been truly remarkable. Typical examples include the UK and Japan in the 1980's, New Zealand in the 1990's and Australia in 2000 (18-22). As late as 2012, Heymann studied children presenting to hospital with acute asthma in San Jose, Costa Rica. Those studies demonstrated that IgE to mite allergens was not only highly prevalent, but also much higher titer than those to other allergens in sera from asthmatic patients (23). In that study, the combination of high titer IgE to mite and a positive test for rhinovirus was very strongly associated with acute asthma (odds ratio $>30$ ). We would also emphasize that in an environment with very high levels of exposure to both HDM and cat (e.g., New Zealand), mite allergens are far more important allergens in relation to asthma than cat allergens are $(20,22)$.

\section{Allergens and Other Molecules in HDM That Trigger Innate Immunity}

During the 1970's and 1980's, dust mite allergens were extensively purified and characterized $(6,7,24)$. Up to the late 1980's it was assumed that the IgE response to these allergens was facilitated by direct allergen recognition and activation of Th2 cells. Prior to this time there was little awareness of innate immunity and of its importance in acting as a bridge to $\mathrm{T}$ cell activation $(25,26)$. We are now aware of more than 30 IgE-binding HDM allergens, many of which have a range of functional biological activities and can directly or indirectly trigger innate immune responses $(27,28)$. Among these, Der p 1, Der p 2, and Der p 23 are identified as the major allergens of D. pteronysinnus (29). Of note, these correspond to group 1, group 2, and group 23 allergens of other species of HDM. Consistent with a prior report, we have shown that among children with asthma that the most important allergens are in the order of Der p $1=$ Der p $2>$ Der p $23(30,31)$. Further, the quantities of IgE to these three components added together can be equivalent to $50-80 \%$ of the amount of IgE to crude dust mite allergen extract. Der p 1 was initially recognized as a serine protease and was demonstrated to have the ability to cleave tight junctions, open up epithelial barriers and remove surface receptors such as CD25 and CD23 $(7,25,26)$. Disruption of epithelium increases allergen uptake by dendritic cells in the mucosa and contributes to tissue damage. 
A Component

\begin{tabular}{ll}
\hline Der $\mathrm{p} 1$ & Cysteine protease \\
\hline Derp 2 & MD2 analog (TLR4 co-receptor) \\
\hline Derp 23 & Peritrophin-like \\
\hline Mite DNA & TLR9 agonist \\
\hline Bacterial DNA & TLR9 agonist \\
\hline Endotoxin & TLR4 agonist, MD2 analog \\
\hline Chitin & TLR2 agonist, dectin 1 agonist \\
\hline -glucan & TLR2 agonist, dectin-1 agonist \\
\hline
\end{tabular}

C

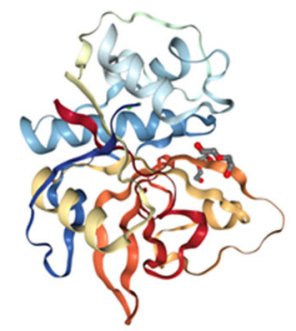

Der $\mathbf{p} 1$

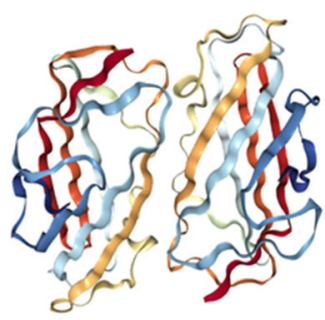

Der $\mathrm{p} 2$
B
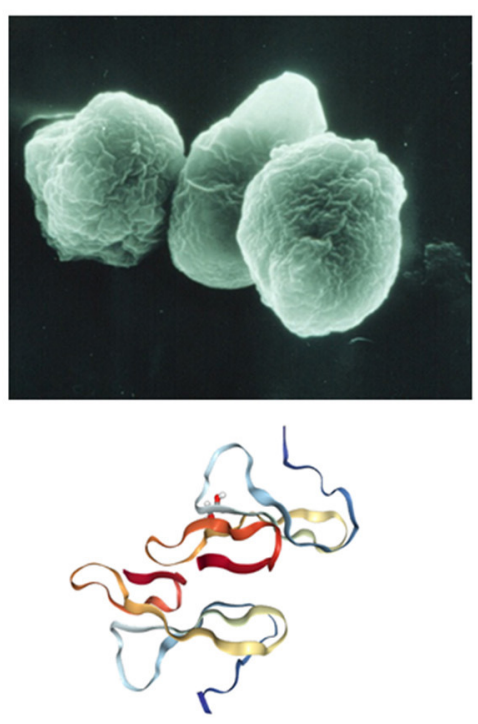

Der p 23

FIGURE 1 | Major HDM allergens and associated constituents present in fecal particles. (A) List of relevant allergens and molecules and their PAMP/DAMP activity. (B) Image of fecal particle (image courtesy of Euan Tovey). (C) Molecular structure of major HDM allergens. Images created with the PDB ID and associated publication, NGL Viewer (16), and RCSB PDB.

Epithelial disruption by Der $\mathrm{p} 1$ also leads to production of extracellular "alarmin" molecules, such as ATP, that have DAMP activity (32). In turn, ATP can promote release of IL-33 from the epithelium. By interacting with its cognate receptor ST2 that is expressed on Th2, ILC2, mast cells and basophils, IL33 is increasingly recognized as an important early mediator of type-2 immune responses $(33,34)$. Of note, emerging evidence suggests that IL-33 can also act directly as a sensor for Der $\mathrm{p}$ 1 and other allergen proteases (35). The second major allergen purified, Der p 2, has structural and biochemical similarity with the TLR4 co-receptor MD-2 (17, 24, 35-37). As such, it may enhance lipopolysaccharide (LPS) effects on TLR4, thereby promoting production of pro-inflammatory cytokines. Der p 23 is a peritrophin-like protein that was recently acknowledged as a third major allergen $(30,38)$. It is speculated to have chitinbinding properties, as has been reported for peritrophin, though this has yet to be experimentally confirmed $(39,40)$. Because Der p 23 is only present in mite fecal particles in minimal quantities it raises some confusion, but it is nonetheless able to induce high titer IgE antibodies in a large proportion of subjects. Several other HDM allergens have also been shown or are thought to be able to activate the innate immune system. For example, Der p 3, Der p 6 and Der p 9 all have protease activity (41). In addition, Der p 5, Der $\mathrm{p} 7$, and Der p 21 share the feature of being lipid-binding proteins (27). Interestingly, a number of important allergens in plants, mammals, and arthropods have been found to be lipidassociated and it is thought that bound lipids can contribute to innate signaling by interacting with TLRs (42). Consistent with this view, Der p 5 has been demonstrated to activate respiratory epithelial cells in a TLR2-dependent manner (43).

As previously mentioned, HDM fecal particles are a rich carrier of not only allergenic proteins but also other components that include mite DNA, bacterial DNA (44), chitin, environmental pollutants, microorganisms (fungi, bacteria, virus, etc.) and microbial compounds (e.g., endotoxin), all of which could act as PAMPs or DAMPs (45). Chitin is a polysaccharide that is abundant in HDM exoskeleton but also found as a component of fecal particles (46). Signaling via TLR2, chitin has been shown to promote Th2 sensitization (47). Another PAMP present in HDM fecal particles (possibly from fungal sources), which has been associated with allergic inflammation is the polysaccharide $\beta$-glucan. There have been some conflicting reports on the downstream signaling that is triggered by $\beta$-glucan, with putative receptors being TLR2, dectin-1, or complement receptors (48-50). TLR4 activation by bacterial endotoxin present in HDM extracts has also been reported $(48,51)$. A detailed understanding of the molecular details of how HDM interact with the innate immune system has major challenges. As outlined by Jacquet (52), the exact composition of house dust is not clearly known and there can be major variations in allergen composition in different dust samples. It is clear, however, that HDM fecal particles are a rich source of allergens and other molecules which have PAMP/DAMP activity. It is likely that the abundance and diversity of such molecules is a major factor that contributes to HDM allergenicity. 


\section{TICK BITES}

Our interest in the relevance of tick bites to allergic disease stems directly from work on a form of delayed allergy to mammalian meat caused by IgE antibodies to the oligosaccharide galactose- $\alpha$ 1, 3-galactose ( $\alpha$-Gal) (53). Because the allergy can manifest after exposure to products other than meat, such as dairy and gelatin, and also certain biologics derived from mammalian cell lines, the allergy is now best known as the $\alpha$-Gal syndrome (AGS) $(54,55)$. Work over the past decade has clearly established that ticks, which are obligate blood-feeding ectoparasites, are the dominant cause of IgE sensitization to $\alpha$-Gal. As a consequence there are reasons to think that $\alpha-\mathrm{Gal}$ is a good model for studying both the relevance of tick saliva and the role of the skin in the origins of allergic immunity (56).

\section{Tick Bites and IgE to Galactose- $\alpha-1,3$-Galactose ( $\alpha$-Gal)}

It is possible that the innate biological activity of $\alpha$-Gal has been studied since the original observation that rabbit red blood cells could activate the alternate pathway of human complement leading to red blood cell lysis (57). It had already been pointed out by Landsteiner and Miller (58) in 1925 that rabbit red cells carried a "B like" antigen that had many features in common with B blood group substance. The full structure of $\alpha$-Gal and appreciation of the "natural" IgG antibody responses to this epitope were later studied by Galili (59). He pointed out that rabbit red cells had particularly high levels of $\alpha$-Gal on their surface, and also proposed an evolutionary mechanism to explain the $100 \%$ loss of $\alpha-\mathrm{Gal}$ in higher primates $(60,61)$. This mechanism proposes that $\sim 25$ million years ago a modest or small percentage of the primate population had loss-offunction mutations in the $\alpha$-1, 3-galactosyltransferase required to synthesize the primate $\alpha-\mathrm{Gal}$ glycan. Members of this small group no longer synthesized $\alpha-\mathrm{Gal}$ and as a consequence were able to make antibodies that could recognize this oligosaccharide expressed on the surface of human pathogens. The hypothesis also includes a highly fatal pandemic caused by a virus or bacterium which carried this epitope. The coup de grâce in this "catastrophic selection" is that those individuals who produced IgG antibodies to $\alpha$-Gal had a selective advantage (61). Only those who had pre-existing anti- $\alpha$-Gal antibodies survived. Our own interest in $\alpha$-Gal arose as a consequence of an investigation into allergic reactions that were occurring upon the first infusion of the monoclonal antibody $(\mathrm{mAb})$ cetuximab in patients with carcinoma of the colon (62). A factor creating special interest was that these reactions were most common in an area focused on Tennessee, Oklahoma, North Carolina, Arkansas, and Virginia. Investigation of pretreatment sera from patients treated with cetuximab in Tennessee established that the reactions were almost exclusively in patients with pre-existing IgE antibodies specific for $\alpha$-Gal epitopes that were expressed on this $\mathrm{mAb}$ (63). Following up on the regional connection, we realized that this was similar to the reported map of maximum incidence of Rocky Mountain Spotted Fever (RMSF) and best explained by the prevalence of a tick which is primarily carried by deer which have been allowed to infest the suburban areas of the Eastern
United States $(64,65)$. It then became clear that this form of allergic disease was also present in several other parts of the world, including Australia, Sweden, France, Germany, and Japan (66). The striking feature from our point of view was that in each of these countries it appeared that the cause of sensitization was tick bites.

The question that is posed is why should IgE sensitization to the $\alpha$-Gal epitope be so strongly associated with tick bites? Relatedly, why do other forms of $\alpha$-Gal exposure, which are sufficient to lead to robust IgM, IgG, and IgA against the glycan in almost all healthy humans, not lead to $\alpha$-Gal $\operatorname{sIgE}(67,68)$ ? It is important to recognize that humans are routinely exposed to bacteria that express $\alpha$-Gal which are part of the normal gut flora $(69,70)$. In addition, mammalian meat (e.g., beef, pork, and lamb) and/or dairy, products which all express $\alpha$-Gal, are also routinely consumed in a Western diet (54). Even so, $\alpha$ Gal sensitization has been uncommon in several populationbased studies in areas where tick bites are rare or absent. For example, neither the syndrome nor IgE antibodies to $\alpha$-Gal have been reported at appreciable levels in Northern Sweden or the mountain states in the Western USA (71-73). There may well be two important parts to these questions: (i) tick bites occur through the skin, whereas "normal" exposure to $\alpha$-Gal occurs via the gut and (ii) constituents present in tick saliva are recognized by the innate immune system and act as robust type-2-promoting adjuvants. It is important to recognize that $\alpha-\mathrm{Gal}$ itself can be considered to have intrinsic PAMP activity given that it is the target of pre-existing IgM, IgG, and IgA antibodies. In addition, $\alpha$-Gal can be recognized by galectin-3, a member of the lectin family with carbohydrate binding domains $(67,74)$.

\section{Tick Bites as a Model for Understanding Allergic Immunity}

In the United States, the primary cause of tick bites in the area where the disease was first recognized is the lone star tick, Amblyomma americanum (64). In other countries the ticks that are recognized as being relevant are generally the most common species biting humans. This may be relevant in the sense that sensitization to the level where the syndrome becomes clinically obvious may require repeated tick bites (75-77). It is also possible that the length of tick mouthparts are relevant to sensitization (or allergic reactions to ticks), as ticks such as A. americanum and Ixodes holocyclus, which are highly associated with $\alpha$-Gal sensitization, have relatively longer mouthparts than other tick species (78). The connection between $\alpha$-Gal sensitization and tick bites has also been bolstered by recent studies showing that the $\alpha$-Gal glycan is expressed in salivary glands of several species of ticks (79-82). Importantly, ticks in which $\alpha$-Gal have been identified include the major ticks associated with $\alpha$-Gal sensitization in the USA (A. americanum) and in Europe ( $I$. ricinus). In the United States there are large areas of the country where Lyme disease, which is transmitted by $l$. scapularis, is common. Despite the fact that I. scapularis can also express $\alpha$-Gal $(79,83)$, this tick does not appear to be a significant 
cause of sensitization to $\alpha-G a l$. The basis for this observation is that areas of the northeast and upper Midwest have few $\alpha$-Gal cases $(71,73)$. Interestingly, the tick bites we studied between 2007 and 2014 had a striking characteristic which was intense itching after the bites. In Central Virginia, a positive answer to the question "have you experienced itching after a bite that lasted more than 2 weeks" was very strongly associated with an IgE response to $\alpha$-Gal approaching an odds ratio of $10(P<$ 0.001) (71). By contrast, a major study on Lyme disease was carried out on Block Island which lies $15 \mathrm{~km}$ off Rhode Island (84). In that study $\sim 1,500$ inhabitants were questioned annually for 10 years about tick bites including the question "Have you experienced itching after a tick bite in the last year." Those subjects who reported itching after a bite on three or more occasions were $82 \%$ less likely to have positive serology to Lyme disease antigens (84). We consider that there are two important messages from these studies of pruritic tick bites. The first is that itching after a tick bite is probably a negative characteristic relative to the transmission of Borrelia burgdorferi and other tickborne pathogens. It can be assumed that itching at the site of a tick bite occurs because of a pre-existing Th2-related immune response, and supports the view that in most cases sensitization to $\alpha-G a l$ (and other tick antigens) requires repeated bites $(75,84)$. The second message is the suggestion that allergic immunity, which involves the elaboration of histamine and other mediators that contribute to pruritis, is an adaptive response that evolved in mammals, in part, to defend against ticks and the pathogens they harbor (see Figure 2) $(1,2,85)$. This message is important because historically some have viewed Th2-related immunity as an anti-inflammatory response that is maladaptive and directed primarily by and for the advantage of the tick $(86,87)$. Part of the confusion about the teleology of type 2 immunity and ticks probably relates to earlier views that suggested that Th1 and Th2 responses represented binary arms of the immune system. However, models of CD4 differentiation that suggested that Th2 immunity reflected an "anti-inflammatory" response have largely fallen out of favor with more nuanced views of CD4 T cell heterogeneity (86-88).

Animal models have also played important roles in informing our understanding of the role of allergic immunity in defense against tick feeding. As early as the 1930's work on guinea pigs revealed that immunity was acquired following a primary tick infestation that provided protection against a subsequent tick infestation(s) (89). As recently reviewed by Karasuyama et al. (78), work over the ensuing decades has revealed important roles for Th2-related cells and mediators-namely basophils, eosinophils, mast cells, and IgE-in conferring this protection. Studies suggest that basophils play a particularly important role in anti-tick defense. First, basophils accumulate at tick bite lesions, both in humans and in animal models, with increasing

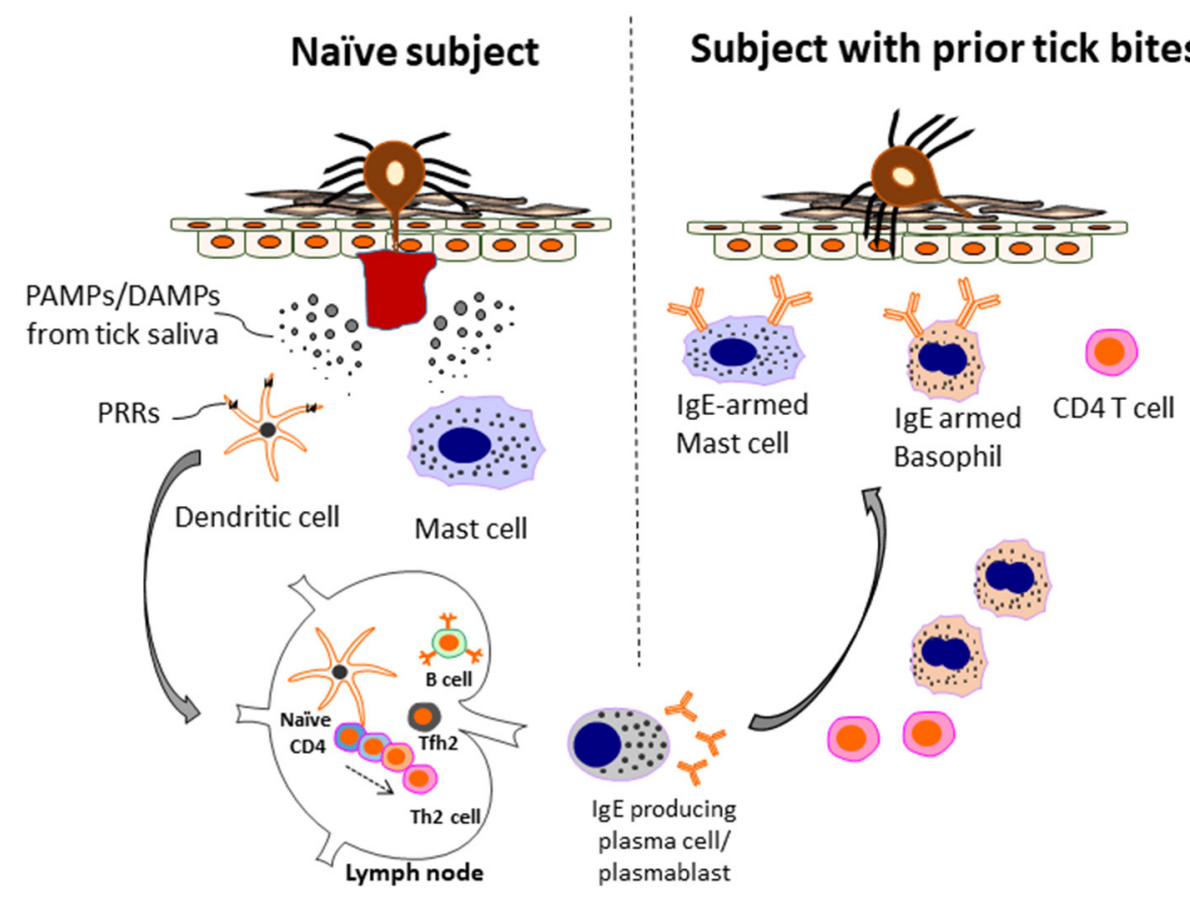

FIGURE 2 | Model of allergic immunity in anti-tick defense. A host without prior tick bites (naïve subject) lacks protective immunity and can have a prolonged tick feed. However, during this initial exposure Th2 cells and lgE-producing B cells are generated. The mechanism includes recognition of PAMPs/DAMPs present in tick saliva by PRRs (e.g., TLR4 and others) present on innate immune cells, such as dendritic cells. In turn, anti-tick lgE binds to mast cells, and basophils via the FceR1 receptor expressed selectively by these cells. Th2 cells and basophils are recruited to the skin. IgE-armed basophils play a particularly important role in acquired tick defense (ATR) to subsequent tick bites. The amount of IgE and number of basophils can be enhanced after repetitive tick bites. As a consequence, both tick feeding and pathogen transmission are impaired. The anti-tick response can include IgE to a-Gal, but also other tick antigens that have yet to be characterized. Adapted by permission from Springer Nature, Current Allergy and Asthma Reports, Galactose- $\alpha-1,3$-galactose: Atypical food allergen or model IgE hypersensitivity; Wilson et al. (56). 


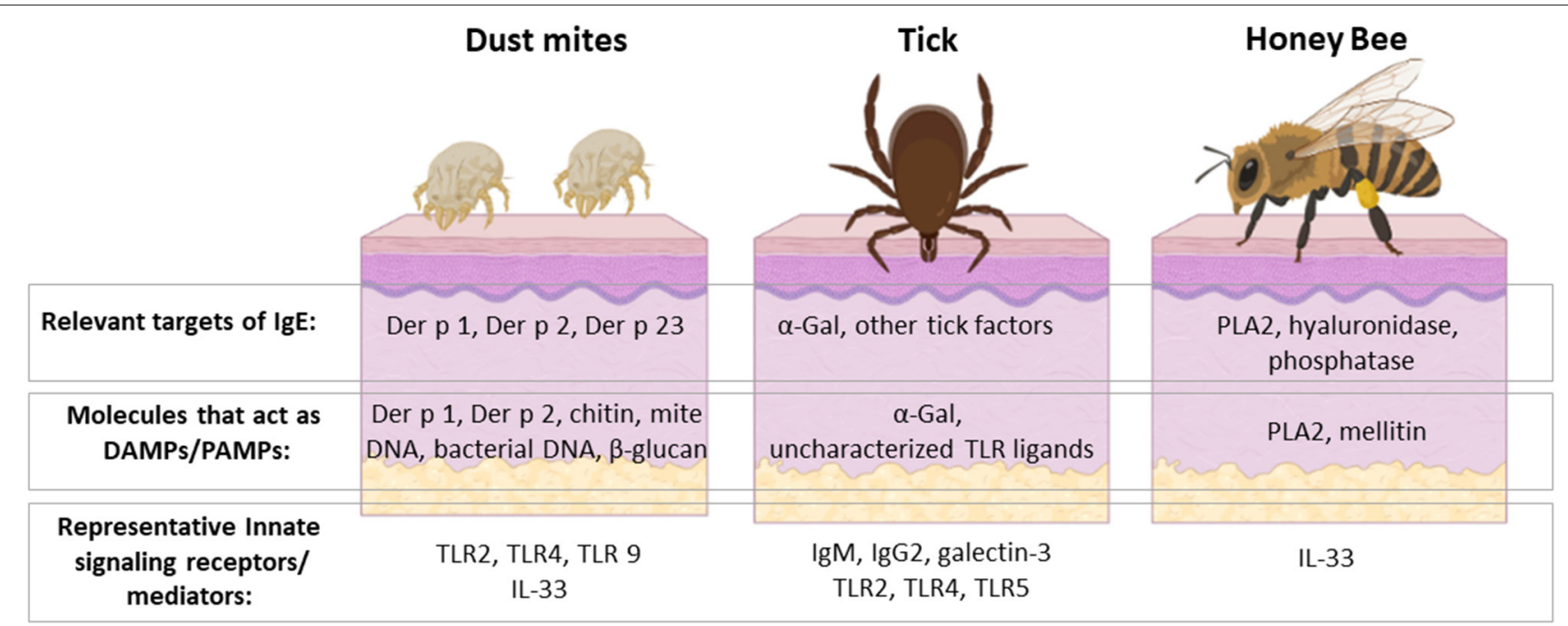

FIGURE 3 | HDM, ticks and venomous insects are important causes of allergic disease with several shared features but also important differences. They are all members of the Arthropod phylum and can interact with the host at the skin barrier, though HDM sensitization occurs dominantly via the respiratory mucosa. The major allergens of HDM, ticks and honey bee are unique from each other, but share the distinction of acting to stimulate host innate immunity. Some allergens, such as Der $\mathrm{p} 2$ and $\alpha$-Gal, are recognized directly by innate immune receptors. Other allergens, such as Der $\mathrm{p} 1$ and PLA 2, have enzymatic activity that leads to activation of innate mediators, including IL-33. Activation of these innate pathways is incompletely understood but leads to induction of Th2 cells and lgE class-switch. Rhinitis, asthma, and anaphylaxis are allergic sequelae that can occur upon re-exposure to the relevant arthropod. On the other hand, these symptoms are manifestations relating to allergic host defenses that have evolved to defend against these organisms. Created with BioRender.com.

frequency with serial tick bites (53, 90-92). Second, ablation of basophils with antibodies or with genetic approaches in animal models leads to a decrease in acquired immunity $(93,94)$. Thus, basophils (and/or mast cells) that become armed with antitick IgE following a primary tick exposure likely contribute to acquired resistance to future tick bites and explain the presence of pruritis in individuals who experience frequent tick bites. Further evidence for this model is the fact that: (i) tick saliva contains several histamine-binding proteins which act to block the activity of host-derived histamine (78) and (ii) administration of an $\mathrm{H} 1$ histamine blocker to mice was sufficient to impair acquired resistance to a 2 nd tick infestation (95). Detailed investigation revealed that the major source of the histamine at the site of the tick lesion was from basophils, not mast cells (95). A recent study introduced extracts from pathogen-free A. americanum larvae subcutaneously into $\mathrm{C} 57 \mathrm{BL} / 6$ mice. Interestingly, there was a marked increase in total serum IgE following sensitization at day 0 and 7 , which was further pronounced with a challenge at day 31 (96). This extract (which did not have detectable $\alpha$ Gal in it) did not induce IgE to $\alpha$-Gal, but did induce IgE specific to the tick extract. However, when exogenous $\alpha$-Gal glycoprotein was spiked into the larval extract, IgE specific for $\alpha$-Gal was detected in the mouse serum. To investigate elements of innate immunity that could be priming the IgE response, a TLR screen was conducted. The screen revealed that the tick extract had robust TLR2, TLR4, and TLR 5 activity. They additionally showed that the response was MyD88 dependent, with a specific B-cell intrinsic role for MyD88 in promoting IgE class switch (96). The specific factors that acted in this model via TLR/MyD88 pathways to promote IgE have yet to be elaborated.

\section{What Are the Factors in Tick Saliva That Contribute to Allergic Immunity?}

Tick saliva contains a large array of biologically active molecules that are dynamically regulated during a blood meal. These factors play a critical role in facilitating a successful blood feed by promoting tick attachment, impairing host hemostasis, and modulating host immunity. The reader is referred to a recent review by Patricia Nuttall which has an excellent overview of the topic (97). Interestingly, Alejandro Cabezas-Cruz and James Valdés asked whether ticks should be considered as venomous ectoparasites. This was based on the observation that several of the protein families identified in tick saliva have close homologs in the venom of snakes, scorpions, and other venomous animals (98). The relevant proteins include defensins, lectins, lipocalins, Kunitz-like peptides, metalloproteases, and phospholipase A2. Non-protein factors, including prostaglandins, nucleosides, endocannabinoids, and microRNA are also present in tick saliva (97). When considering the role of tick saliva on host immunity one must consider that there are factors in tick saliva that act to impair the host immune response and also factors that are recognized by the innate immune system which prime type 2 immunity. This dynamic interplay between tick and host has been described by some as an "immunologic arms race" (99). Examples of tick salivary factors that can impair the host response include histamine-binding proteins, the purine nucleoside adenosine, and the protein Salp15, which is produced by I. scapularis and been shown to impair CD4 T cell proliferation (87). However, the question most germane to the current discussion is: what are the factors that are recognized by the host immune system in the skin that contribute to $\operatorname{IgE}$ induction? 
Clearly there must be potent Th2-promoting PAMP/DAMPs present in tick saliva, but at this point the role of specific factors is not well characterized. Examples of molecules that have been proposed or could be relevant in driving IgE class switch include prostaglandin E2 (100) and/or phospholipase A2 (PLA2) (101). PLA2 is an intriguing possibility as it is: (i) found in abundance in the saliva of $A$. americanum, (ii) honey bee PLA2 is the major allergen of bee venom, and (iii) honey bee PLA2 has intrinsic PAMP activity (101-103). Given the complexity of tick saliva it would not be surprising if other PAMPs/DAMPs with Th2-promoting activity, including those that are lipid-based, are discovered in the future. It is also important to consider that there are communities of bacteria, viruses and eukaryotes present in tick saliva that could act as PAMPs (104). Finally, host factors that are elicited indirectly as a consequence of damaged epithelium, such as IL-33 or ATP, also warrant further investigation $(32,35)$.

\section{CONCLUSION}

The scientific community has made great strides over the past few decades in unraveling the pathways that contribute to IgE sensitization. Research increasingly suggests that allergic immunity evolved as a rapid defense mechanism to combat helminths, ecto-parasites, and venomous animals. This hypothesis is supported by significant gains in our knowledge of the innate immune system and also by insights into allergic immune responses elicited by two acarid arthropods with very different modes of interaction with the host surface. Allergic sensitization to HDM fecal particles occurs dominantly via the respiratory mucosa, whereas tick bites promote IgE sensitization through the skin. Work on dust mites in the 1970's provided early clues about the importance of particles in allergen sensitization. It also hinted that biologically complex molecules, such as

\section{REFERENCES}

1. Palm NW, Rosenstein RK, Medzhitov R. Allergic host defences. Nature. (2012) 484:465-72. doi: 10.1038/nature11047

2. Galli SJ, Starkl P, Marichal T, Tsai M. Mast cells and IgE in defense against venoms: possible "good side" of allergy? Allergol Int. (2016) 65:315. doi: 10.1016/j.alit.2015.09.002

3. Pulendran B, Artis D. New paradigms in type 2 immunity. Science. (2012) 337:431-5. doi: 10.1126/science.1221064

4. Maeda K, Caldez MJ, Akira S. Innate immunity in allergy. Allergy. (2019) 74:1660-74. doi: 10.1111/all.13788

5. Stoltz LP, Cristiano LM, Dowling APG, Wilson JM, Platts-Mills TAE, Traister RS. Could chiggers be contributing to the prevalence of galactose-alpha-1,3galactose sensitization and mammalian meat allergy? J Allergy Clin Immunol Pract. (2019) 7:664-6. doi: 10.1016/j.jaip.2018.07.014

6. Lind P, Korsgaard J, Lowenstein H. Detection and quantitation of Dermatophagoides antigens in house dust by immunochemical techniques. Allergy. (1979) 34:319-26. doi: 10.1111/j.1398-9995.1979.tb04373.x

7. Chapman MD, Platts-Mills TA. Purification and characterization of the major allergen from Dermatophagoides pteronyssinus-antigen P1. J Immunol. (1980) 125:587-92.

8. Tovey ER, Chapman MD, Platts-Mills TA. Mite faeces are a major source of house dust allergens. Nature. (1981) 289:592-3. doi: 10.1038/289592a0 those in mite feces, would be relevant to priming an allergic response. More recent work suggests that proteolytic disruption of the epithelial barrier is an indirect mechanism whereby HDM and other environmental allergens drive innate pathways. Our understanding of the factors in tick saliva that contribute to IgE class-switch and Th2-priming remain in their infancy, but there are good reasons to think that tick saliva is a rich source of molecules with such biological activity. The robust allergic response that occurs to both tick bites and HDM fecal particles is likely explained by conserved features, including: (i) the delivery of multiple PAMPs/DAMPs into a local area of the skin or mucosa and (ii) effects which disrupt the epithelial barrier. The latter is clearly consistent with the epithelial barrier hypothesis of allergic disease, as recently summarized by Cezmi Akdis (105). Work to clarify the specific factors that contribute to innate activation is ongoing, but has been hampered by a reliance on the use of animal models and cell-based co-culture systems. Emerging tools and technologies can be expected to play an important role in promoting further advances. Ongoing investigations into ticks, mites and also venomous insects have the potential to provide more information about the origins and development of allergic immunity (Figure 3).

\section{AUTHOR CONTRIBUTIONS}

BK, LE, TP-M, and JW contributed to the writing and graphics of the manuscript. All authors contributed to the article and approved the submitted version.

\section{FUNDING}

This study was supported by R21 AI-152447 (LE), R37 AI-20565 (TP-M), and AAAAI Faculty Development Award (JW).
9. Tovey ER, Chapman MD, Wells CW, Platts-Mills TA. The distribution of dust mite allergen in the houses of patients with asthma. Am Rev Respir Dis. (1981) 124:630-5.

10. Eisenbarth SC, Piggott DA, Huleatt JW, Visintin I, Herrick CA, Bottomly K. Lipopolysaccharide-enhanced, toll-like receptor 4-dependent T helper cell type 2 responses to inhaled antigen. J Exp Med. (2002) 196:164551. doi: 10.1084/jem.20021340

11. Lee CG, Da Silva CA, Lee JY, Hartl D, Elias JA. Chitin regulation of immune responses: an old molecule with new roles. Curr Opin Immunol. (2008) 20:684-9. doi: 10.1016/j.coi.2008.10.002

12. Medzhitov R, Janeway CA Jr. Innate immunity: the virtues of a nonclonal system of recognition. Cell. (1997) 91:2958. doi: 10.1016/S0092-8674(00)80412-2

13. O'Neill LA, Golenbock D, Bowie AG. The history of Toll-like receptors - redefining innate immunity. Nat Rev Immunol. (2013) 13:453-60. doi: 10.1038/nri3446

14. Matzinger P. The danger model: a renewed sense of self. Science. (2002) 296:301-5. doi: 10.1126/science.1071059

15. Medzhitov R. Toll-like receptors and innate immunity. Nat Rev Immunol. (2001) 1:135-45. doi: 10.1038/35100529

16. Rose AS, Bradley AR, Valasatava Y, Duarte JM, Prlic A, Rose PW. NGL viewer: web-based molecular graphics for large complexes. Bioinformatics. (2018) 34:3755-8. doi: 10.1093/bioinformatics/bty419 
17. Swanson MC, Campbell AR, Klauck MJ, Reed CE. Correlations between levels of mite and cat allergens in settled and airborne dust. J Allergy Clin Immunol. (1989) 83:776-83. doi: 10.1016/0091-6749(89)90014-6

18. Miyamoto T, Johansson S, Ito K, Horiuchi Y. Atopic allergy in Japanese subjects: studies primarily with radioallergosorbent test. J Allergy Clin Immunol. (1974) 53:9-19. doi: 10.1016/0091-6749(74)90094-3

19. Sporik R, Holgate ST, Platts-Mills TA, Cogswell JJ. Exposure to house-dust mite allergen (Der p I) and the development of asthma in childhood. A prospective study. N Engl J Med. (1990) 323:502-7. doi: 10.1056/NEJM199008233230802

20. Erwin EA, Wickens K, Custis NJ, Siebers R, Woodfolk J, Barry D, et al. Cat and dust mite sensitivity and tolerance in relation to wheezing among children raised with high exposure to both allergens. J Allergy Clin Immunol. (2005) 115:74-9. doi: 10.1016/j.jaci.2004.10.030

21. Peat JK, Tovey E, Toelle BG, Haby MM, Gray EJ, Mahmic A, et al. House dust mite allergens. A major risk factor for childhood asthma in Australia. Am J Respir Crit Care Med. (1996) 153:141-6. doi: 10.1164/ajrccm.153.1.8542107

22. Sears MR, Herbison GP, Holdaway MD, Hewitt CJ, Flannery EM, Silva PA. The relative risks of sensitivity to grass pollen, house dust mite and cat dander in the development of childhood asthma. Clin Exp Allergy. (1989) 19:419-24. doi: 10.1111/j.1365-2222.1989.tb02408.x

23. Soto-Quiros M, Avila L, Platts-Mills TA, Hunt JF, Erdman DD, Carper H, et al. High titers of IgE antibody to dust mite allergen and risk for wheezing among asthmatic children infected with rhinovirus. J Allergy Clin Immunol. (2012) 129:1499-505.e5. doi: 10.1016/j.jaci.2012.03.040

24. Heymann PW, Chapman MD, Aalberse RC, Fox JW, Platts-Mills TA. Antigenic and structural analysis of group II allergens (Der f II and Der $\mathrm{p}$ II) from house dust mites (Dermatophagoides spp). J Allergy Clin Immunol. (1989) 83:1055-67. doi: 10.1016/0091-6749(89)90447-8

25. Wan H, Winton HL, Soeller C, Tovey ER, Gruenert DC, Thompson PJ, et al. Der $\mathrm{p} 1$ facilitates transepithelial allergen delivery by disruption of tight junctions. J Clin Invest. (1999) 104:123-33. doi: 10.1172/JCI5844

26. Gough L, Schulz O, Sewell HF, Shakib F. The cysteine protease activity of the major dust mite allergen Der p 1 selectively enhances the immunoglobulin E antibody response. J Exp Med. (1999) 190:1897902. doi: $10.1084 / \mathrm{jem} .190 .12 .1897$

27. Jacquet A, Robinson C. Proteolytic, lipidergic and polysaccharide molecular recognition shape innate responses to house dust mite allergens. Allergy. (2020) 75:33-53. doi: 10.1111/all.13940

28. Abu Khweek A, Kim E, Joldrichsen MR, Amer AO, Boyaka PN. Insights into mucosal innate immune responses in house dust mite-mediated allergic asthma. Front Immunol. (2020) 11:534501. doi: 10.3389/fimmu.2020.534501

29. Posa D, Perna S, Resch Y, Lupinek C, Panetta V, Hofmaier S, et al. Evolution and predictive value of IgE responses toward a comprehensive panel of house dust mite allergens during the first 2 decades of life. J Allergy Clin Immunol. (2017) 139:541-9.e8. doi: 10.1016/j.jaci.2016.08.014

30. Mueller GA, Randall TA, Glesner J, Pedersen LC, Perera L, Edwards LL, et al. Serological, genomic and structural analyses of the major mite allergen Der p 23. Clin Exp Allergy. (2016) 46:365-76. doi: 10.1111/cea.12680

31. Keshavarz B, Wilson J, Lidholm J, Custovic A, Cooper P, Heymann P, et al. Dust mite allergen components in children from Costa Rica, Ghana, and Ecuador: more evidence that Der p 23 is a major allergen. J Allergy Clin Immunol. (2020) 145:Ab206. doi: 10.1016/j.jaci.2019.12.218

32. Dai X, Tohyama M, Murakami M, Shiraishi K, Liu S, Mori H, et al. House dust mite allergens induce interleukin 33 (IL-33) synthesis and release from keratinocytes via ATP-mediated extracellular signaling. Biochim Biophys Acta Mol Basis Dis. (2020) 1866:165719. doi: 10.1016/j.bbadis.2020.165719

33. Cayrol C, Girard JP. Interleukin-33 (IL-33): a nuclear cytokine from the IL-1 family. Immunol Rev. (2018) 281:154-68. doi: 10.1111/imr.12619

34. Martin NT, Martin MU. Interleukin 33 is a guardian of barriers and a local alarmin. Nat Immunol. (2016) 17:122-31. doi: 10.1038/ni.3370

35. Cayrol C, Duval A, Schmitt P, Roga S, Camus M, Stella A, et al. Environmental allergens induce allergic inflammation through proteolytic maturation of IL-33. Nat Immunol. (2018) 19:375-85. doi: 10.1038/s41590-018-0067-5

36. Trompette A, Divanovic S, Visintin A, Blanchard C, Hegde RS, Madan R, et al. Allergenicity resulting from functional mimicry of a Toll-like receptor complex protein. Nature. (2009) 457:585-8. doi: 10.1038/nature07548
37. Derewenda U, Li J, Derewenda Z, Dauter Z, Mueller GA, Rule GS, et al. The crystal structure of a major dust mite allergen Der p 2, and its biological implications. J Mol Biol. (2002) 318:18997. doi: 10.1016/S0022-2836(02)00027-X

38. Weghofer M, Grote M, Resch Y, Casset A, Kneidinger M, Kopec J, et al. Identification of Der p 23, a peritrophin-like protein, as a new major Dermatophagoides pteronyssinus allergen associated with the peritrophic matrix of mite fecal pellets. J Immunol. (2013) 190:305967. doi: $10.4049 /$ jimmunol.1202288

39. Soh WT, Le Mignon M, Suratannon N, Satitsuksanoa P, Chatchatee P, Wongpiyaboron J, et al. The house dust mite major allergen Der $\mathrm{p}$ 23 displays O-glycan-independent IgE reactivities but no chitin-binding activity. Int Arch Allergy Immunol. (2015) 168:150-60. doi: 10.1159/0004 42176

40. Mika A, Goh P, Holt DC, Kemp DJ, Fischer K. Scabies mite peritrophins are potential targets of human host innate immunity. PLoS Negl Trop Dis. (2011) 5:e1331. doi: 10.1371/journal.pntd.0001331

41. Reithofer M, Jahn-Schmid B. Allergens with protease activity from house dust mites. Int J Mol Sci. (2017) 18:1368. doi: 10.3390/ijms18071368

42. Jappe U, Schwager C, Schromm AB, Gonzalez Roldan N, Stein K, Heine $\mathrm{H}$, et al. Lipophilic allergens, different modes of allergen-lipid interaction and their impact on asthma and allergy. Front Immunol. (2019) 10:122. doi: 10.3389/fimmu.2019.00122

43. Pulsawat P, Soongrung T, Satitsuksanoa P, Le Mignon M, Khemili S, Gilis D, et al. The house dust mite allergen Der $\mathrm{p} 5$ binds lipid ligands and stimulates airway epithelial cells through a TLR2-dependent pathway. Clin Exp Allergy. (2019) 49:378-90. doi: 10.1111/cea.13278

44. Douwes J, Zuidhof A, Doekes G, Zee SVD, Wouters I, Boezen HM, et al. $(1 \rightarrow 3)$ - $\beta$-d-glucan and endotoxin in house dust and peak flow variability in children. Am J Respir Crit Care Med. (2000) 162:134854. doi: 10.1164/ajrccm.162.4.9909118

45. Rizzo MC, Naspitz CK, Fernandez-Caldas E, Lockey RF, Mimica I, Sole D. Endotoxin exposure and symptoms in asthmatic children. Pediatr Allergy Immunol. (1997) 8:121-6. doi: 10.1111/j.1399-3038.1997.tb0 0164.x

46. Elieh Ali Komi D, Sharma L, Dela Cruz CS. Chitin and its effects on inflammatory and immune responses. Clin Rev Allergy Immunol. (2018) 54:213-23. doi: 10.1007/s12016-017-8600-0

47. Choi JP, Lee SM, Choi HI, Kim MH, Jeon SG, Jang MH, et al. House dust mite-derived chitin enhances Th2 cell response to inhaled allergens, mainly via a TNF- $\alpha$-dependent pathway. Allergy Asthma Immunol Res. (2016) 8:362-74. doi: 10.4168/aair.2016.8.4.362

48. Ryu JH, Yoo JY, Kim MJ, Hwang SG, Ahn KC, Ryu JC, et al. Distinct TLR-mediated pathways regulate house dust mite-induced allergic disease in the upper and lower airways. J Allergy Clin Immunol. (2013) 131:54961. doi: 10.1016/j.jaci.2012.07.050

49. Ito T, Hirose K, Norimoto A, Tamachi T, Yokota M, Saku A, et al. Dectin1 plays an important role in house dust mite-induced allergic airway inflammation through the activation of $\mathrm{CD} 11 \mathrm{~b}+$ dendritic cells. J Immunol. (2017) 198:61-70. doi: 10.4049/jimmunol.1502393

50. Hadebe S, Kirstein F, Fierens K, Redelinghuys P, Murray GI, Williams DL, et al. beta-Glucan exacerbates allergic airway responses to house dust mite allergen. Respir Res. (2016) 17:35. doi: 10.1186/s12931-016-0352-5

51. Liu CF, Drocourt D, Puzo G, Wang JY, Riviere M. Innate immune response of alveolar macrophage to house dust mite allergen is mediated through TLR2/4 co-activation. PLoS One. (2013) 8:e75983. doi: 10.1371/journal.pone.00 75983

52. Jacquet A. Characterization of innate immune responses to house dust mite allergens: pitfalls and limitations. Front Allergy. (2021) 2:662378. doi: 10.3389/falgy.2021.662378

53. Platts-Mills TAE, Commins SP, Biedermann T, van Hage M, Levin M, Beck LA, et al. On the cause and consequences of $\operatorname{IgE}$ to galactosealpha-1,3-galactose: a report from the National Institute of Allergy and Infectious Diseases Workshop on Understanding IgE-Mediated Mammalian Meat Allergy. J Allergy Clin Immunol. (2020) 145:106171. doi: $10.1016 /$ j.jaci.2020.01.047

54. Fischer J, Yazdi AS, Biedermann T. Clinical spectrum of alphaGal syndrome: from immediate-type to delayed immediate-type 
reactions to mammalian innards and meat. Allergo J Int. (2016) 25:55-62. doi: 10.1007/s40629-016-0099-Z

55. Platts-Mills TAE, Li RC, Keshavarz B, Smith AR, Wilson JM. Diagnosis and management of patients with the alpha-Gal syndrome. J Allergy Clin Immunol Pract. (2020) 8:15-23.e1. doi: 10.1016/j.jaip.2019. 09.017

56. Wilson JM, Schuyler AJ, Schroeder N, Platts-Mills TA. Galactose-alpha-1,3galactose: atypical food allergen or model IgE hypersensitivity? Curr Allergy Asthma Rep. (2017) 17:8. doi: 10.1007/s11882-017-0672-7

57. Platts-Mills TA, Ishizaka K. Activation of the alternate pathway of human complements by rabbit cells. J Immunol. (1974) 113:348-58.

58. Landsteiner K, Miller CP. Serological studies on the blood of the primates: III. Distribution of serological factors related to human isoagglutinogens in the blood of lower monkeys. J Exp Med. (1925) 42:86372. doi: 10.1084 /jem.42.6.863

59. Galili U. Anti-Gal: an abundant human natural antibody of multiple pathogeneses and clinical benefits. Immunology. (2013) 140:1-11. doi: 10.1111/imm.12110

60. Galili U, Clark MR, Shohet SB, Buehler J, Macher BA. Evolutionary relationship between the natural anti-Gal antibody and the Gal alpha 1-3Gal epitope in primates. Proc Natl Acad Sci U S A. (1987) 84:136973. doi: 10.1073/pnas.84.5.1369

61. Galili U. Evolution in primates by "Catastrophic-selection" interplay between enveloped virus epidemics, mutated genes of enzymes synthesizing carbohydrate antigens, and natural anti-carbohydrate antibodies. Am J Phys Anthropol. (2019) 168:352-63. doi: 10.1002/ajpa.23745

62. Chung CH, Mirakhur B, Chan E, Le QT, Berlin J, Morse M, et al. Cetuximabinduced anaphylaxis and IgE specific for galactose-alpha-1,3-galactose. $N$ Engl J Med. (2008) 358:1109-17. doi: 10.1056/NEJMoa074943

63. Platts-Mills TA, Hilger C, Jappe U, Hage M, Gadermaier G, Spillner E, et al. Carbohydrate epitopes currently recognized as targets for IgE antibodies. Allergy. (in press). doi: 10.1111/all.14802

64. Commins SP, James HR, Kelly LA, Pochan SL, Workman LJ, Perzanowski MS, et al. The relevance of tick bites to the production of IgE antibodies to the mammalian oligosaccharide galactose-alpha-1,3-galactose. J Allergy Clin Immunol. (2011) 127:1286-93.e6. doi: 10.1016/j.jaci.2011.02.019

65. Steinke JW, Platts-Mills TA, Commins SP. The alpha-gal story: lessons learned from connecting the dots. J Allergy Clin Immunol. (2015) 135:58996; quiz 97. doi: 10.1016/j.jaci.2014.12.1947

66. Cabezas-Cruz A, Hodzic A, Roman-Carrasco P, Mateos-Hernandez L, Duscher GG, Sinha DK, et al. Environmental and molecular drivers of the alpha-Gal syndrome. Front Immunol. (2019) 10:1210. doi: 10.3389/fimmu.2019.01210

67. Hamadeh RM, Galili U, Zhou P, Griffiss JM. Anti-alpha-galactosyl immunoglobulin A (IgA), IgG, and $\operatorname{IgM}$ in human secretions. Clin Diagn Lab Immunol. (1995) 2:125-31. doi: 10.1128/cdli.2.2.125-1 31.1995

68. Aguilar R, Ubillos I, Vidal M, Balanza N, Crespo N, Jimenez A, et al. Antibody responses to alpha-Gal in African children vary with age and site and are associated with malaria protection. Sci Rep. (2018) 8:9999. doi: 10.1038/s41598-018-28325-w

69. Galili U, Mandrell RE, Hamadeh RM, Shohet SB, Griffiss JM. Interaction between human natural anti-alpha-galactosyl immunoglobulin $\mathrm{G}$ and bacteria of the human flora. Infect Immun. (1988) 56:1730-7. doi: 10.1128/IAI.56.7.1730-1737.1988

70. Hilger C, Fischer J, Wolbing F, Biedermann T. Role and mechanism of galactose-alpha-1,3-galactose in the elicitation of delayed anaphylactic reactions to red meat. Curr Allergy Asthma Rep. (2019) 19:3. doi: 10.1007/s11882-019-0835-9

71. Wilson JM, Keshavarz B, Retterer M, Workman LJ, Schuyler AJ, McGowan EC, et al. A dynamic relationship between two regional causes of IgE-mediated anaphylaxis: alpha-Gal syndrome and imported fire ant. J Allergy Clin Immunol. (2021) 147:643-52.e7. doi: 10.1016/j.jaci.2020. 05.034

72. Commins SP, Kelly LA, Ronmark E, James HR, Pochan SL, Peters EJ, et al. Galactose-alpha-1,3-galactose-specific $\operatorname{IgE}$ is associated with anaphylaxis but not asthma. Am J Respir Crit Care Med. (2012) 185:72330. doi: $10.1164 / \mathrm{rccm} .201111-2017 \mathrm{OC}$
73. Binder AM, Commins SP, Altrich ML, Wachs T, Biggerstaff BJ, Beard CB, et al. Diagnostic testing for galactose-alpha-1,3-galactose, United States, 2010 to 2018. Ann Allergy Asthma Immunol. (2021) 126:411-6.e1. doi: 10.1016/j.anai.2020.12.019

74. Greenwald AG, Jin R, Waddell TK. Galectin-3-mediated xenoactivation of human monocytes. Transplantation. (2009) 87:44-51. doi: 10.1097/TP.0b013e318191e6b4

75. Hashizume H, Fujiyama T, Umayahara T, Kageyama R, Walls AF, Satoh T. Repeated Amblyomma testudinarium tick bites are associated with increased galactose-alpha-1,3-galactose carbohydrate IgE antibody levels: a retrospective cohort study in a single institution. J Am Acad Dermatol. (2018) 78:1135-41.e3. doi: 10.1016/j.jaad.2017.12.028

76. Kim MS, Straesser MD, Keshavarz B, Workman L, McGowan EC, PlattsMills TAE, et al. IgE to galactose-alpha-1,3-galactose wanes over time in patients who avoid tick bites. J Allergy Clin Immunol Pract. (2020) 8:3647.e2. doi: 10.1016/j.jaip.2019.08.045

77. Fischer J, Lupberger E, Hebsaker J, Blumenstock G, Aichinger E, Yazdi AS, et al. Prevalence of type I sensitization to alpha-gal in forest service employees and hunters. Allergy. (2017) 72:1540-7. doi: 10.1111/all. 13156

78. Karasuyama H, Miyake K, Yoshikawa S. Immunobiology of acquired resistance to ticks. Front Immunol. (2020) 11:601504. doi: 10.3389/fimmu.2020.601504

79. Crispell G, Commins SP, Archer-Hartman SA, Choudhary S, Dharmarajan G, Azadi P, et al. Discovery of alpha-gal-containing antigens in north American tick species believed to induce red meat allergy. Front Immunol. (2019) 10:1056. doi: 10.3389/fimmu.2019.01056

80. Apostolovic D, Mihailovic J, Commins SP, Wijnveld M, Kazimirova M, Starkhammar $\mathrm{M}$, et al. Allergenomics of the tick Ixodes ricinus reveal important alpha-Gal-carrying IgE-binding proteins in red meat allergy. Allergy. (2019) 75:217-20. doi: 10.1111/all.13978

81. Araujo RN, Franco PF, Rodrigues H, Santos LC, McKay CS, Sanhueza CA, et al. Amblyomma sculptum tick saliva: alpha-Gal identification, antibody response and possible association with red meat allergy in Brazil. Int $J$ Parasitol. (2016) 46:213-20. doi: 10.1016/j.ijpara.2015.12.005

82. Fischer J, Riel S, Fehrenbacher B, Frank A, Schaller M, Biedermann T, et al. Spatial distribution of alpha-gal in Ixodes ricinus - a histological study. Ticks Tick Borne Dis. (2020) 11:101506. doi: 10.1016/j.ttbdis.2020.1 01506

83. Cabezas-Cruz A, Espinosa PJ, Alberdi P, Simo L, Valdes JJ, MateosHernandez L, et al. Tick galactosyltransferases are involved in alphaGal synthesis and play a role during Anaplasma phagocytophilum infection and Ixodes scapularis tick vector development. Sci Rep. (2018) 8:14224. doi: 10.1038/s41598-018-32664-z

84. Burke G, Wikel SK, Spielman A, Telford SR, McKay K, Krause PJ, et al. Hypersensitivity to ticks and Lyme disease risk. Emerg Infect Dis. (2005) 11:36-41. doi: 10.3201/eid1101.040303

85. Cabezas-Cruz A, Hodzic A, Mateos-Hernandez L, Contreras M, de la Fuente J. Tick-human interactions: from allergic klendusity to the alpha-Gal syndrome. Biochem J. (2021) 478:1783-94. doi: 10.1042/BCJ20200915

86. Wikel SK, Alarcon-Chaidez FJ. Progress toward molecular characterization of ectoparasite modulation of host immunity. Vet Parasitol. (2001) 101:27587. doi: 10.1016/S0304-4017(01)00556-8

87. Kazimirova M, Stibraniova I. Tick salivary compounds: their role in modulation of host defences and pathogen transmission. Front Cell Infect Microbiol. (2013) 3:43. doi: 10.3389/fcimb.2013.00043

88. Jankovic D, Feng CG. CD $4(+) \mathrm{T}$ cell differentiation in infection: amendments to the Th1/Th2 axiom. Front Immunol. (2015) 6:198. doi: 10.3389/fimmu.2015.00198

89. Trager W. Acquired immunity to ticks. J Parasitol Urbana. (1939) 25:5778. doi: $10.2307 / 3272160$

90. Brown SJ, Barker RW, Askenase PW. Bovine resistance to Amblyomma americanum ticks: an acquired immune response characterized by cutaneous basophil infiltrates. Vet Parasitol. (1984) 16:147-65. doi: 10.1016/0304-4017(84)90016-5

91. Monteiro GE, Bechara GH. Cutaneous basophilia in the resistance of goats to Amblyomma cajennense nymphs after repeated infestations. Ann N Y Acad Sci. (2008) 1149:221-5. doi: 10.1196/annals.1428.026 
92. Kageyama R, Fujiyama T, Satoh T, Keneko Y, Kitano S, Tokura Y, et al. The contribution made by skin-infiltrating basophils to the development of alpha-gal syndrome. Allergy. (2019) 74:1805-7. doi: 10.1111/all.13794

93. Brown SJ, Galli SJ, Gleich GJ, Askenase PW. Ablation of immunity to Amblyomma americanum by anti-basophil serum: cooperation between basophils and eosinophils in expression of immunity to ectoparasites (ticks) in guinea pigs. J Immunol. (1982) 129:790-6.

94. Wada $\mathrm{T}$, Ishiwata $\mathrm{K}$, Koseki $\mathrm{H}$, Ishikura $\mathrm{T}$, Ugajin $\mathrm{T}$, Ohnuma $\mathrm{N}$, et al. Selective ablation of basophils in mice reveals their nonredundant role in acquired immunity against ticks. J Clin Invest. (2010) 120:286775. doi: 10.1172/JCI42680

95. Tabakawa Y, Ohta T, Yoshikawa S, Robinson EJ, Yamaji K, Ishiwata K, et al. Histamine released from skin-infiltrating basophils but not mast cells is crucial for acquired tick resistance in mice. Front Immunol. (2018) 9:1540. doi: 10.3389/fimmu.2018.01540

96. Chandrasekhar JL, Cox KM, Loo WM, Qiao H, Tung KS, Erickson LD. Cutaneous exposure to clinically relevant lone star ticks promotes IgE production and hypersensitivity through $\mathrm{CD} 4(+) \mathrm{T}$ cell- and MyD88-dependent pathways in mice. J Immunol. (2019) 203:81324. doi: 10.4049/jimmunol.1801156

97. Nuttall PA. Wonders of tick saliva. Ticks Tick Borne Dis. (2019) 10:47081. doi: 10.1016/j.ttbdis.2018.11.005

98. Cabezas-Cruz A, Valdes JJ. Are ticks venomous animals? Front Zool. (2014) 11:47. doi: 10.1186/1742-9994-11-47

99. Sa-Nunes A, Oliveira CJF, Ribeiro JM. Mast cells and basophils: from malevolent design to coevolutionary arms race. Trends Parasitol. (2020) 36:655-9. doi: 10.1016/j.pt.2020.05.003

100. Cabezas-Cruz A, Mateos-Hernandez L, Chmelar J, Villar M, de la Fuente J. Salivary prostaglandin E2: role in tick-induced allergy to red meat. Trends Parasitol. (2017) 33:495-8. doi: 10.1016/j.pt.2017.03.004
101. Bowman AS, Gengler CL, Surdick MR, Zhu K, Essenberg RC, Sauer JR, et al. A novel phospholipase A2 activity in saliva of the lone star tick, Amblyomma americanum (L.). Exp Parasitol. (1997) 87:12132. doi: 10.1006/expr.1997.4201

102. Marichal T, Starkl P, Reber LL, Kalesnikoff J, Oettgen HC, Tsai M, et al. A beneficial role for immunoglobulin $\mathrm{E}$ in host defense against honeybee venom. Immunity. (2013) 39:963-75. doi: 10.1016/j.immuni.2013.10.005

103. Palm NW, Rosenstein RK, Yu S, Schenten DD, Florsheim E, Medzhitov R. Bee venom phospholipase A2 induces a primary type 2 response that is dependent on the receptor ST2 and confers protective immunity. Immunity. (2013) 39:976-85. doi: 10.1016/j.immuni.2013.10.006

104. Greay TL, Gofton AW, Paparini A, Ryan UM, Oskam CL, Irwin PJ. Recent insights into the tick microbiome gained through next-generation sequencing. Parasit Vectors. (2018) 11:12. doi: 10.1186/s13071-0172550-5

105. Akdis CA. Does the epithelial barrier hypothesis explain the increase in allergy, autoimmunity and other chronic conditions? Nat Rev Immunol. (in press). doi: 10.1038/s41577-021-00538-7

Conflict of Interest: The authors declare that the research was conducted in the absence of any commercial or financial relationships that could be construed as a potential conflict of interest.

Copyright (c) 2021 Keshavarz, Erickson, Platts-Mills and Wilson. This is an openaccess article distributed under the terms of the Creative Commons Attribution License (CC BY). The use, distribution or reproduction in other forums is permitted, provided the original author(s) and the copyright owner(s) are credited and that the original publication in this journal is cited, in accordance with accepted academic practice. No use, distribution or reproduction is permitted which does not comply with these terms. 